Abstracta Iranica Abstracta Iranica

Revue bibliographique pour le domaine irano-aryen

Volume 42-43 | 2021

Comptes rendus des publications de 2019-2020

\title{
Antonio Panaino. A Walk through the Iranian Heavens. Spherical and Non-Spherical Cosmographic Models in the Imagination of Ancient Iran and Its Neighbors
}

Alessia Zubani

\section{(2) OpenEdition}

1 Journals

Édition électronique

URL : https://journals.openedition.org/abstractairanica/52908

DOI : 10.4000/abstractairanica.52908

ISSN : 1961-960X

Éditeur :

CNRS (UMR 7528 Mondes iraniens et indiens), Éditions de l'IFRI

Référence électronique

Alessia Zubani, « Antonio Panaino. A Walk through the Iranian Heavens. Spherical and Non-Spherical Cosmographic Models in the Imagination of Ancient Iran and Its Neighbors », Abstracta Iranica [En ligne] Volume 42-43 | 2021, document 2, mis en ligne le 30 juillet 2021, consulté le 14 décembre 2022. URL http://journals.openedition.org/abstractairanica/52908; DOI : https://doi.org/10.4000/ abstractairanica.52908

Ce document a été généré automatiquement le 14 décembre 2022.

Tous droits réservés 


\title{
Antonio Panaino. A Walk through the Iranian Heavens. Spherical and Non- Spherical Cosmographic Models in the Imagination of Ancient Iran and Its Neighbors
}

\author{
Alessia Zubani
}

\section{RÉFÉRENCE}

Antonio Panaino. A Walk through the Iranian Heavens. Spherical and Non-Spherical

Cosmographic Models in the Imagination of Ancient Iran and Its Neighbors. Leiden-Boston :

Brill, 2019, p. 220.

1 En se penchant sur la notion de «sphère » dans le cadre cosmologique et astrologique du monde iranien ancien et tardo-antique, l'A. offre une discussion sur la cosmographie iranienne qui tient en compte des interactions culturelles avec les civilisations grecques, mésopotamiennes et indiennes. Les sources persanes préislamiques révèlent des modèles cosmographiques anciens dans lesquels trois cieux sont superposés. Puisant ses origines dans la tradition mésopotamienne (comme l'attestent des textes acadiens du I ${ }^{\mathrm{er}}$ millénaire av. n.è.), ce schéma superpose au ciel des étoiles, ceux de la lune (en position centrale) et du soleil (en haut). L'A. montre que dans les époques successives ce modèle sera modifié en raison des interactions avec d'autres traditions scientifiques et philosophiques. En particulier, il se penche sur la question de la circulation de concepts et notions aristotéliciens, néoplatoniciens et indiens dans le monde iranien tardo-antique. L'uranographie persane développée avant et après la conquête arabo-islamique a été en mesure d'harmoniser la représentation traditionnelle des cieux avec un modèle sphérique, en acceptant également des motifs en contradiction avec les modèles et concepts cosmographiques anciens (tels que les 
notions et schémas ptolémaïques). Cette coexistence témoigne alors du dialogue multiculturel et multireligieux ayant caractérisé le monde iranien ancien et médiéval. L'A. montre également la place réservée à l'époque sassanide et post-sassanide à certains problèmes cosmographiques et uranographiques dans les débats entre courants philosophiques et théologiques.

2 Cet ouvrage propose une étude claire et détaillée du développement de la cosmographie iranienne ancienne et tardo-antique, en mettant en relief les dynamiques de circulation de savoirs et les notions scientifiques et philosophiques dans le vaste espace eurasiatique. En outre, il fournit une analyse du concept de sphère développé dans le monde iranien, en montrant qui a été le fruit d'un processus lent et tardif d'élaboration théorique.

\section{AUTEURS}

\section{ALESSIA ZUBANI}

Labex HaStec, EPHE 